\title{
Structural health monitoring of grandstands: a review.
}

\author{
Miguel Ángel Gómez-Casero Fuentes ${ }^{1}$, Rafael Castro-Triguero ${ }^{1}$, Enrique García-Macías ${ }^{1}$, Rafael Gallego Sevilla ${ }^{2}$, and José \\ Cabrera $^{3}$ \\ ${ }^{1}$ University of Cordoba. Department of Mechanics, Cordoba, Spain \\ ${ }^{2}$ University of Granada, Department of Structural Mechanics, Granada, Spain \\ ${ }^{3}$ SILOS-Cordoba, Cordoba, Spain
}

\begin{abstract}
This article is a state of the art about Grandstands. The Grandstands are slender structures designed to accommodate a large number of people, which are specially under the actions of wind and the human-structure interaction. Over the years, it has been discuss of this topic, although still the number of publications still remain low. The human-structure interaction is a complex issue, where the loads may have different behaviours, depending many factors, including: type of audience (active or passive), public behaviour (jumping, walking, running, clapping, vandal loads), type of event (sports, concerts, meeting), position and posture of the individual, even influences the type of seat (with or without back, stiffness). However, the structure will behave differently when empty or fully occupied. Another load to consider is the wind, especially when the structure has a roof, screens, large-scale advertising, etc. These two types of loads can interact together, which implies an increase in the normal number of load combinations to consider. There are biomechanical models of human behaviour, used for design these types of structures. In addition, there are mathematical models to simulate the behaviour of the Grandstands by numerical methods. In recent years, all these models are throwing good results, against laboratory tests performed. It has also been monitored real Grandstands. This paper compiles all existing information on this topic.
\end{abstract}

\section{Introduction}

Grandstands are slender structures designed to accommodate a large number of people. There are several criteria for classification based on use (sports events, shows or religious uses), its morphology (grandstands covered, uncovered, scaffold type, extendible) or the material used (concrete, steel, composite or other materials).

In the design of grandstands, there are two loads types which we should pay special attention: wind loads and human-structure interaction. Over the years, it has been discussed of this topic, although the number of publications still remains low.

Wind loads are important when grandstands have roof and other elements affected by the wind: large billboards, screens, etc.

The other loads are human-structure interaction. The public mass has not been considered as a dynamic load. The dynamic load has been simplified as dead load (static load). Due to the use of new stronger and lighter materials, its consideration has been changed. Public masses add a large amount compared with the mass of the structure. Therefore the effect of people is an important factor to be considered.

Besides, it has been demonstrated that the combination between the wind and the human-induced forces require a more complex calculation. Some authors mention two important aspects on wind loads [1]: (1) high wind and empty structure, or (2) low wind and full structure [2].

\section{Special loads to consider}

\subsection{Human-structure interaction}

The mass of occupants on grandstand may reach more than 20 percent of the structural mass. This indicates that the effects of humans can be significant [3] and simplification in a static load is invalid.

There are two types of loads produced by public [4]:

- Passive public: They are static public, motionless. They may be sitting or standing. The behaviour of the structure changes depending on the posture of the public. The public may have damping effect.

- Active public: They are continually moving, causing differences in the vibration of the structure.

\subsubsection{Effect of human-structure interaction}

There are two approaches: from the impact of humaninduced forces to the effect on the dynamic properties of the structure. Dynamic forces are produced by activities such as: walking, jumping, running, dancing, clapping, etc.

\footnotetext{
${ }^{\mathrm{a}}$ Corresponding author: p62gofum $@$ uco.es
} 
The human-induced forces have traditionally been approximated by Fourier series, assuming the loads as perfectly periodic [5-6]. Although there are alternative approaches defining human-induced forces as autospectral density functions in the frequency domain. As mentioned above, the dynamic forces induced by crowds, are a topic of growing concern. However, it has not been thoroughly investigated yet. In fact, the dependency of the nature and magnitude of induced forces on the size of the active crowd and perceptible motion of the structure is currently not clear [7].

It has been shown that the dynamic load caused by crowd is greater than produced by a single person. Moreover, it has been observed that the relationship between increasing the amount of load and the number of people is not linear. The dynamic load depends of the synchronization of crowd [8-10]. The synchronization increases with visual contact and the influence of noise in the public [11-12].

There are two types of public synchronization: can be deliberate or unintentional. Deliberate synchronization is caused for example by aerobic classes, vandal loading [7].

Unintentional synchronization of pedestrians with structural movements is another case of human-structure interaction. This synchronization can lead to vibrations strong enough to disturb people in movement [13-14]. Therefore the structures may become unusable or unsafe due to the panic that might occur. This effect has been observed in several footbridges as the Millennium Bridge [15-18].

During the opening of Millennium Bridge in June 2000 there were large lateral vibrations [19]. Subsequently increasing the modal damping was solved the problem [20]. Another pedestrian bridge that suffered the same effect was the Lardal Bridge in Norway [21].

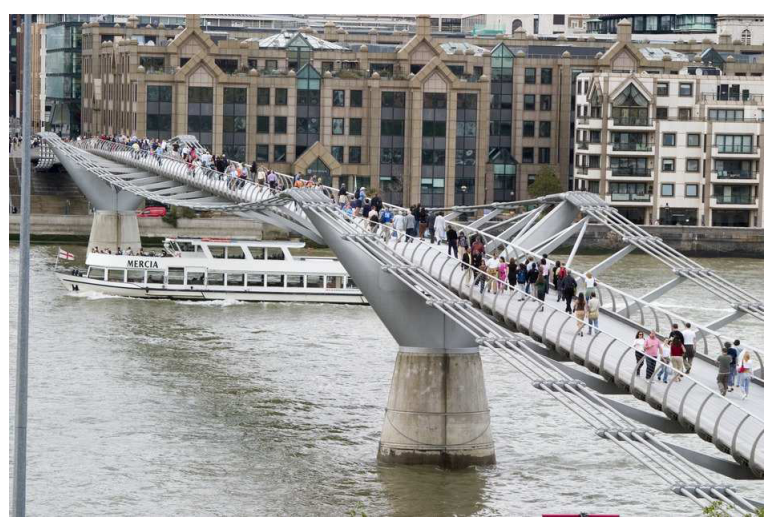

Figure 1. The Millennium Bridge, London.

Human occupants present on civil engineering structures do not only excite the structure, but also they can simultaneously alter the modal properties of the structure they occupy [7]. There is still little information about the properties of occupied structures or models of the occupants. For this reason, in civil engineering design the influence of human occupants in the dynamics of the vibration system is neglected.
In many cases is considered the influence of the occupants in the dynamic properties of civil engineering structures such as additional mass to the structure. In the design guide 'Applied Technology Council' this methodology is applied by adding a percentage of the weight of the occupants, depending on the positions of the occupants and the natural frequency of the structure. Moreover other articles show the difference between the public sitting in seats with or without back.

Likewise, a significant increase in the damping of the structure has been demonstrated due to occupants. [2225]. Further investigations also revealed that an occupant absorbs significantly more energy than concrete plate on which the person is supported [26-28]. Nevertheless, this beneficial effect has not been included in building codes. Human models represented as a single additional mass are used only in the 'National Building Code of Canada' (NBC). It is a guide to human-induced vibrations in floors or walkways [29-31]. Although increases in damping observed cannot be explained by these models of additional single mass.

Civil engineering structures whose natural frequencies are above certain limits are not necessary to design against human-induced vibrations [31-33]. Those limits are based on the ability of human occupants to induce significant forces in the lower frequencies. In the case of vertical modes, the BS EN 1991-1-7:2006 [32] specifies $8.4 \mathrm{~Hz}$ and guidance of temporary structures [34] specifies $6 \mathrm{~Hz}$ natural frequency limit in empty structures. However, measurements made by [35] demonstrated that crowds can reduce the fundamental frequencies of relatively light structures empty assembly as high as $16 \mathrm{~Hz}$ to approximately $5 \mathrm{~Hz}$, which is below the limits 8.4 and $6 \mathrm{~Hz}$. Therefore, must be revised the design by limiting the natural frequency. Whereas, [14] recommend a detailed design of the structure for pedestrian bridges, when the vertical natural frequency is less than $5 \mathrm{~Hz}$ and the lateral frequency is less than 2.5 $\mathrm{Hz}$, in addition they proposed a number of solutions including:

- Stiffen the structure in the right direction or shorten the length of the bridge.

- Add mass: thus the influence of human-induced vibration is reduced. Proportional stiffness to maintain the natural frequency.

- Damping systems: the energy dissipated is increased. They may affect to a range of frequencies and can also be installed later.

On the other hand, the modelling of occupants as additional mass (imposed by [31]) cannot predict such strong frequency reductions.

In summary, human occupation of civil engineering structures can lead to increased damping, a significant reduction of fundamental natural frequencies and also to additional natural frequencies, meaning additional modes of vibration [7]. These effects must be deducted precisely to allow the design and evaluation of safety and economy in civil engineering structures against human-structure vibrations. Therefore, appropriate dynamic models of human occupants have to be used. Because grandstands are slender structures and they can be subjected to high 
levels of human-induced forces and their dynamic properties can be changed significantly.

\subsubsection{Dynamic models in civil engineering}

Most individual biomechanical models of human have been developed for aerospace and mechanical engineering, as well as health issues. Models can represent a full body or only particular portions [36-37].

The simplest biomechanical model is that of a single degree of freedom (SDOF) [38]. These can get good approximations to experimental and analytical FRF.

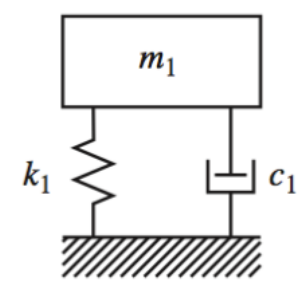

Figure 2. SDOF human body model [45].

The damped SDOF model became a model with two degrees of freedom (2-DOF). Experimentally it was find that often appear two peaks in the FRF when people is sitting, and generally when they are stand. The additional degree of freedom (DOF) was available in two different forms: attached to the first DOF [39] or fully independent at the first DOF [40-41].
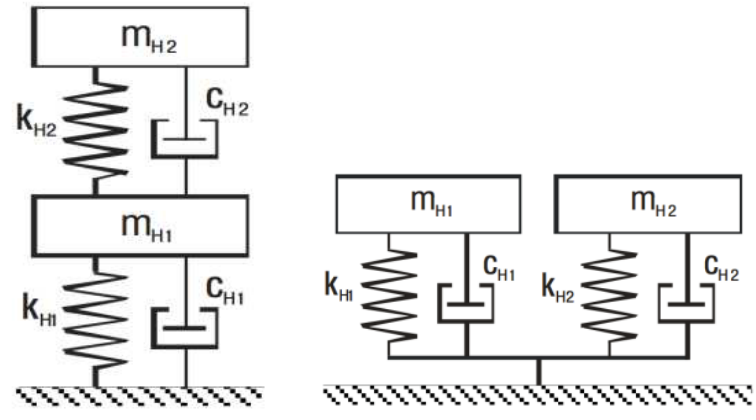

Figure 3. 2-DOF and 2-SDOF human body model [7].

J. Sim presented the problem of the loads produced by crowds using a simplified system with a small number of degrees of freedom representing simultaneously the crowd and structure [42-43]. He started with models until 5 -DOF, keeping in mind the structure and models 2-DOF of active and passive people. However, in other researches, the problem was presented with an active and passive representation of crowds with a smaller freedom, resulting in a 3-DOF [44-45].

Thus, other authors have obtained high levels of accuracy with this type of model, consisting of an S-DOF structure and DOF additional occupants.

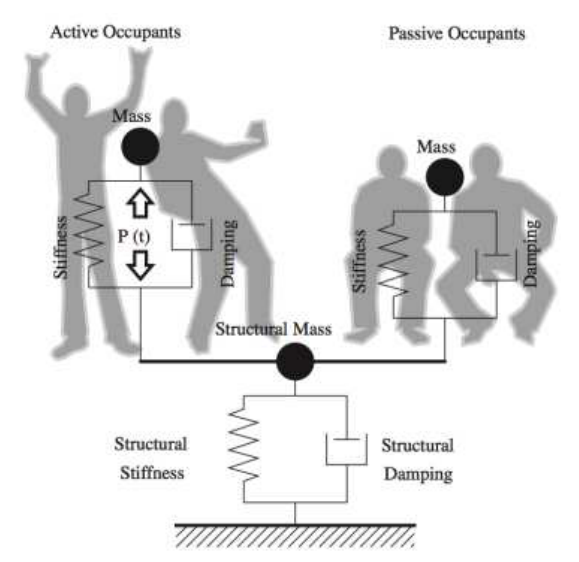

Figure 4. 3-DOF human body model [44-45].

Most biomechanical research to determine the full body vibration was focused on the vertical vibration of seated people [46]. In fewer researches they participated humans standing [47-53] or observed horizontal vibrations $[46,54-57]$.

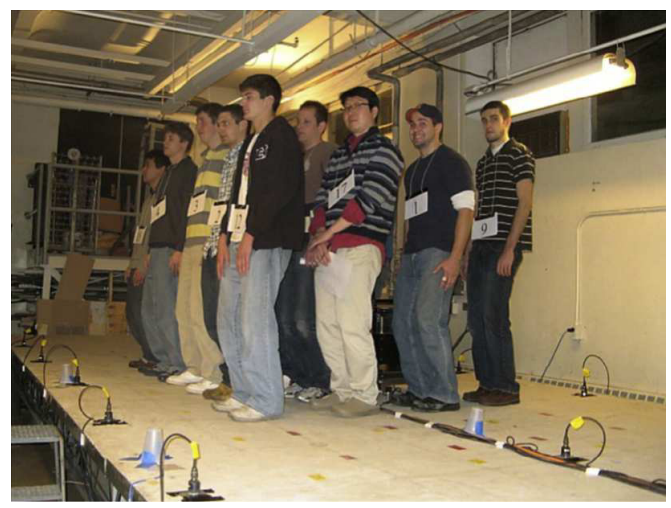

Figure 5. Experimental testing with bent knees posture and dense distribution [53].

When the results of biomechanical research of dynamic models of the complete human body are used in civil engineering, several important issues need to be considered. On one hand, the human body is a complex nonlinear dynamic system, which has properties that differs between different people (between subject variability) and between individuals themselves $[39,58$ 59]. Secondly, vertical vibrations of sitting or standing people are controlled by a much damped mode. This mode has a natural frequency between 4 and $6 \mathrm{~Hz}$, and damping coefficient was tested between $20 \%$ and $50 \%$. Furthermore, the properties of the human body are strongly dependent on the magnitude of vibration.

Nevertheless, vibration levels present in civil engineering are considerably smaller than those used by the biomechanics to derive human dynamic models [59]. Therefore, it is necessary verify and possibly refine before adopting biomechanical models to model human occupants in civil engineering structures. In addition, all biomechanical models presented by authors only represent people individually. However, the modelling occupants groups are essential to model the dynamic behaviour of the total structure, which is a point of concern in the civil engineering design. 
A detailed knowledge of the dynamic properties of the combination human-structure is needed to predict the response of the structure to human-induced vibrations. Therefore, it is increasingly more research on the effect of this interaction and attempt to model human occupants and dynamic systems. These models have been tested experimentally and analytically.

Currently the influence of human occupants in civil engineering structures cannot predict mathematically, for example on the grandstands. Because they are a complex issue and there are not still $100 \%$ reliable models.

Some of these experimental researches can be found in detailed studies in the literature $[26-28,35,51,53,60$ 67].
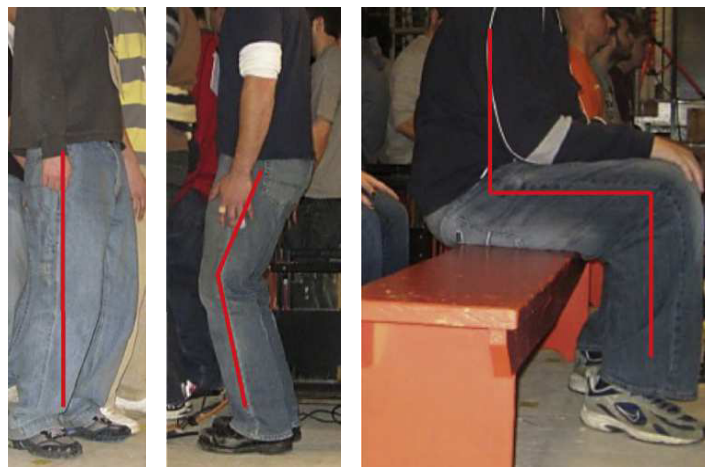

Figure 6. Different human postures: straight knees, bent knees and seated [53].

For experiments, a series of instruments and facilities are necessary to determine dynamic forces produced by humans in structures: walking, running, jumping, cheering, etc. Available equipment can be traditional: force plate, template, foot pressure, instrumented treadmills; or developed with new technologies: optical motion tracking systems (optoelectronic technology) and non-optical motion tracking systems (inertial sensors) [68].
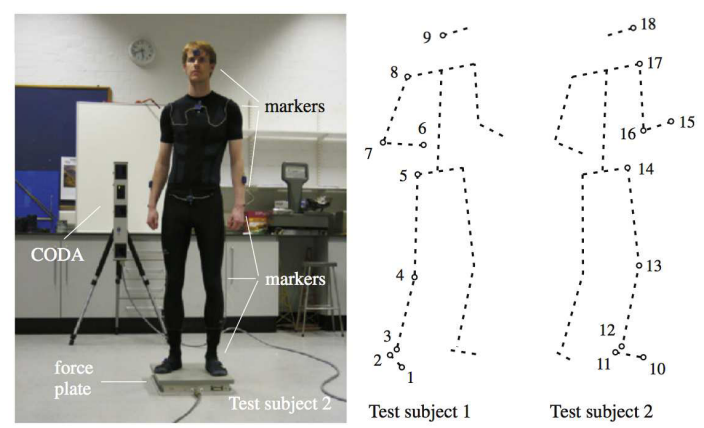

Figure 7. Experimental setup and, human body model and arrangement of markers [51].

Also great stadiums have been monitored for extended periods of data acquisition. They have been obtained data with full and empty structure, as in the case of monitoring Giuseppe Meazza Stadium in Milan [69].

Grandstands have been modelled by structural analysis software, such as ANSYS, ABAQUS, SAP2000, etc. Some of these examples have been published in numerous articles [70-71].

There are researches that develop analytical response representations of the structure to active crowd and passive crowd loads. One was developed using Filtered Gaussian white noise processes to approximate the loading terms representing an active crowd. This model includes a biodynamic model concentrates with a single degree of freedom to reflect passive spectators occupying the structure [72].

\subsection{Wind: special considerations}

Actions due to wind loads on these structures (grandstands), must take special care for two main reasons:

- Grandstands with roof and other elements affected by the wind: such as screens, large billboards, walls of stands, etc.

- Combination between wind and human-induced loads.

An example of the first case is the study of a cantilever roof, where the dynamic parameters of 4 real cases are obtained and are compared with finite element model [73]. Good results were obtained. Although in this case was not considered the human-structure interaction, considering in the calculation only covers.

Also it has been made studies in wind tunnel to check the real effect on structures of smaller scale [74-75]. In one study were considered several hypotheses distribution on the cover with different inclinations [74].

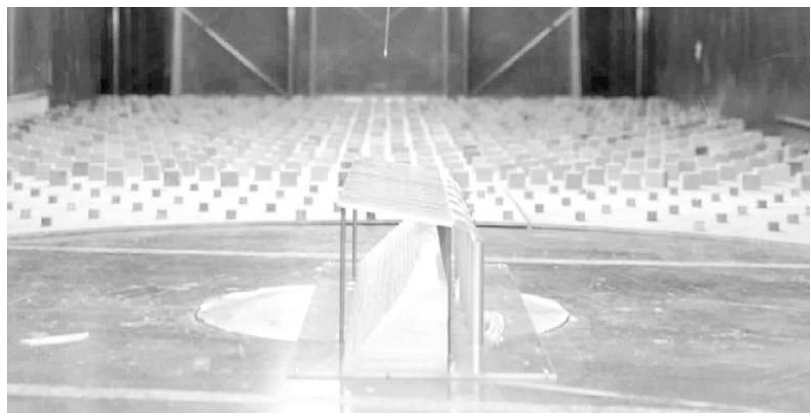

Figure 8. Wind tunnel model of cantilevered roof and grandstand [74].

There is an article that presents a number of cases of collapse of demountable grandstands [2]. Authors conclude possible causes: excessive or unexpected loading (human-structure interaction or wind loads), performance of structural components (foundation, superstructure, stability system), erection process, or materials employed. They recommend examine the structures after assembled, access control, analysis effect of human-induced loads and efficient design of supports.

Likewise, if there is not a dynamic study about structural behaviour under human-induced loads, they recommend apply a coefficient to the weight of occupants. Specially on active public.

The grandstands design has two extreme cases:

- High wind and empty structure. 
- Low wind and full structure.

Researchers recommend realise a full dynamic study for the security in grandstands design. Besides, in grandstands design, must add more load combinations in the calculation in order to model the structural behaviour correctly. This results from the combined action of human-structure interaction and wind loads.

\section{Conclusions}

Civil engineering structures require a lot of attention for their safety, because the importance for the society. Grandstands need special attention, because they are structures that can accommodate a large number of people. They must be reliable and confortable structures. As discussed throughout this work, in this type of construction, we must place special emphasis on structural design, specifically in wind loads and the human-induced forces.

The human-structure interaction has two points of view: the effect of vibrations in human-induced forces and changes dynamic properties produced for presence of people.

The first case has to do with the synchronization of the public. To greater simultaneity of all individuals, greater the dynamic loads. In addition, this synchronization depends of the visual contact with other individuals and the environment (clapping in concerts, jump in sport events, etc.)

The other point of view, have to do with the change in dynamic properties. Human occupation can produce variations in the natural frequency (fundamental frequency reduction), greater damping (individuals can absorb more energy than the structure itself) and create additional vibration modes (additional natural frequencies). These changes depend of the mass contributed by the crowd, as well as the position on the structure (standing, bending, sitting with or without back). These effects have been demonstrated in laboratory experiments, where have been observed that individuals absorb more energy than the structure itself. This effect is beneficial for structural integrity, but it is not included in most building codes.

After discussing this, it is necessary to indicate the need to accurately predict these effects to allow for design and evaluation of safety and economy of civil engineering structures, against human-induced vibrations.

In order to make accurate assessments of these slender structures you must use appropriate dynamic models that represent as closely as possible the behaviour of human crowd on the structural elements.

In summary, in the design of slender structures should be specially careful in its calculation. Because they can be subjected to high levels of human-induced forces and thus can significantly modify dynamic properties and appear resonance phenomenon.

In response to the actions due to the wind, there are numerous documents, and they are also included in the most building codes. Today are still doing studies of their behaviour such as wind tunnel tests.
The biggest problem with the wind is observed when it acts together with the human-induced forces. Because these forces can modify dynamic properties of the structure. Therefore we must pay attention to calculate the combination of actions.

\section{References}

1. J. F. Dickie, Struct. Eng, 81-86 (1983)

2. V. L. de Brito, R. L. Pimentel, J. Perform. Constr. Facil. 151-159 (2009)

3. C. A. Jones, P. Reynolds, A. Pavic, J. Sound Vibr., 1531-1566 (2011)

4. L. Pedersen, Proceedings of the $31^{\text {st }}$ IMAC, 4, 155161 (2013)

5. G. Pernica, Canadian Acoustics, (1990)

6. S. C. Kerr, Doctoral thesis (1998)

7. R. Sachse, A. Pavic, P. Reynolds, Shock Vib. Dig., 3-18, (2003)

8. Y. Fujino, B. M. Pacheco, S. I. Nakamura, P. Warnitchai, Earthq. Eng. Struct. Dyn., 741-758 (1993)

9. P. van Staalduinen, W. Courage, IABSE reports (1994)

10. F. Venuti, L. Bruno, Phys. Life Rev., 176-206 (2009)

11. E. T Ingólfsson, Doctoral thesis (2011)

12. A. Hamam, A. Ebrahimpour, R. L. Sack, W. N. Patten, J. Struct. Eng., 1468-1474 (1996)

13. P. Dallard, T. Fitzpatrick, A. Flint, A. Low, R. R. Smith, M. Willford, The Structural Engineer (IEstructE), 78 (23/24) (2000)

14. S. Stoyanoff, M. Hunter, RWDI, Issue no. 15 (2003)

15. D. Parker, New Civil Engineer (ICE) (2000)

16. T. Fitzpatrick, Royal Academy of Engineering, 4-28 (2001)

17. D. E. Newland, Int. Congress on Sound and Vibration (2003)

18. J. H. Mcdonald, The Royal Society of London (2008)

19. P. Dallard, T. Fitzpatrick, A. Flint, A. Low, R. R. Smith, M. Willford, M. Roche, J. Bridge Eng., 412417 (2001)

20. D. E. Newland, Int. J. Acoust. Vib., 9-14 (2003)

21. A. Rønnquist, E. Strømmen, Departament of Structural Engineering (2005)

22. D. Manheim, W. Honeck, Conference _ ASCE 115 (1987)

23. A. Ebrahimpour, R. L. Sack, P. D. van Kleek, Comput. Struct., 1313-1319 (1991)

24. R. L. Pimentel, P. Waldron, Proceedings of the ICIES, 648-657 (1996)

25. T. Ji, The Structural Engineer, 12-13 (2003)

26. J. M. Brownjohn, Proccedings of the APVC, 13-15 (1999)

27. J. M. Brownjohn, Shock Vib., 315-323 (2001)

28. J. M. Brownjohn, X. Zheng, Conference on Experimental Mechanics, 489-493 (2001)

29. NBCC-1995 (1995) 
30. D. E. Allen, D. M. Onysko, T. M Murray, Applied Technology Council (ATC), 1 (1999)

31. HMSO, Departament of National Heritage, $\mathbf{5}^{\text {th }}$ edition (2008)

32. Eurocode 1 (2006)

33. IStructE/DTLR/DCMS, The Institution of Structural Engineers (2001)

34. IStructE, The Institution of Structural Engineers (2008)

35. B. R. Ellis, T. Ji, Proceedings of the ICE-Structures and Buildings, 1-9 (1997)

36. C. T. Farley, O. González, J. Biomech., 181-186 (1996)

37. C. T. Farley, D. C. Morgenroth, J. Biomech., 267273 (1999)

38. Y. Matsumoto, M. J. Griffin, J. Sound Vibr., 431451 (2003)

39. R. Sachse, A. Pavic, P. Reynolds, J. Sound Vibr., 461-480 (2004)

40. C. W. Suggs, C. F. Abrams, L. F. Stikeleather, Ergonomics, 79-90 (1969)

41. L. Wei, M. J. Griffin, J. Sound Vibr., 855-874 (1998)

42. J. H. Sim, Doctoral thesis (2006)

43. J. H. Sim, A. Blakeborough, M. Williams, Proceedings of the ICE-Structures and Buildings, 261-272 (2006)

44. J. H. Sim, A. Blakeborough, M. Williams, Shock Vib., 261-270 (2007)

45. C. A. Jones, P. Reynolds, A. Pavic, J. Sound Vibr., 1531-1566 (2011)

46. T. Fairley, M. Griffin, J. Sound Vibr., 299-306 (1990)

47. R. R. Coermann, Hum. Factors, 227-253 (1962)

48. Y. Matsumoto, In UK Informal Group Meeting on Human Response to Vibration, 18-20 (1996)

49. Y. Matsumoto, M. J. Griffin, J. Sound Vibr., 85-107 (1998)

50. Y. Matsumoto, M. J. Griffin, J. Sound Vibr., 691704 (2000)

51. V. Racic, J. M. Brownjohn, A. Pavic, J. Sound Vibr., 3397-3416 (2010)

52. P. Mazzoleni, E. Zappa, Mech. Syst. Signal Proc., 112 (2012)

53. K. A. Salyards, Y. Hua, Eng. Struct., 103-110 (2015)

54. P. Holmlund, R. Lundström, J. Sound Vibr., 801812 (1998)

55. N. J. Mansfield, R. Lundström, Aviat. Space Environ. Med. (ASEM), 1166-1172 (1999)

56. N. J. Mansfield, R. Lundström, J. Biomech., 12691278 (1999)

57. S. Nhleko, M. S. Williams, A. Blakeborough, J. Stebbins, J. Sound Vibr., 2856-2871 (2013)

58. ISO 2001, Mechanical vibration and shock (2001)

59. M. J. Griffin, Academic press (2012)

60. B. R. Ellis, T. Ji, J. D. Littler, IABSE Reports, 277277 (1994)

61. S. Falati, PhD Thesis (1999)

62. A. Pavic, C. H. Yu, J. Brownjohn, P. Reynolds, IMAC XX (2002)
63. S. Yao, J. R. Wright, A. Pavic, P. Reynolds, J. Sound Vibr., 150-165 (2006)

64. V. Racic, A. Pavic, Mech. Syst. Signal Proc., 30373059 (2010)

65. A. J. Comer, A. Blakeborough, M. S. Williams, J. Sound Vibr., 442-454 (2013)

66. D. Wang, T. Ji, Q. Zhang, E. Duarte, J. Eng. Mech., 406-417 (2013)

67. G. Busca, A. Cappellini, S. Manzoni, M. Tarabini, M. Vanali, J. Sound Vibr., 5641-5652 (2014)

68. V. Racic, A. Pavic, J. M. Brownjohn, Shock Vib., 53-67 (2013)

69. M. Vanali, A. Cigada, EESMS 2009, 103-109 (2009)

70. J. Yuan, L. He, F. Fan, C. Liu, K. Zhang, EURODYN 2014 (2014)

71. B. R. Ellis, T. Ji, J. D. Littler, Proceedings of the ICE-Structures and Buildings, 355-365 (2000)

72. O. Rokoš, J. Máca, Adv. Eng. Softw., 85-94 (2014)

73. C. W. Letchford, R. O. Denoon, G. Johnson, A. Mallam, Eng. Struct., 1085-1090 (2002)

74. J. G. Zhao, K. M. Lam, J. Wind Eng. Ind. Aerodyn., 1867-1880 (2002)

75. K. M. Lam, A. P. To, J. Wind Eng. Ind. Aerodyn., 345-357 (1995) 